small fraction of the university resources earmarked for undergraduates and research to postgraduate education aimed specifically at acquiring professional diplomas.

The proposal that clinical tutors in the non-teaching hospitals in the region should be more actively engaged in the affairs of their local medical school may entail some universities amending their regulations to accommodate such a development. It can be accomplished only provided academic standards are maintained in the process and at the same time undergraduate schools do not find themselves swamped or threatened with being swamped by postgraduate teachers, perhaps representing a few specialties that are particularly active in the postgraduate training field. An effective but acceptable system of representation on academic boards is needed.

General training programmes vary in length between the specialties. In psychiatry it is currently three years. If a trainee is to experience the full regional course described above he will need to be in approved rotational posts within the region for three and a half years, say one year as an SHO with promotion to registrar for two and a half years. While this system operates in our own department it does not operate throughout the region. Flexibility in appointment and re-appointment and perhaps redefinition of some contracts are needed to accommodate the training needs of various specialties.

If registrars and senior registrars are to undertake more research work as part of their training programmes (and this is highly desirable since clinical practice is clinical research and everyone should know the ground rules) this will require more supervisory time and will have further staffing implications. Not all specialties lend themselves to in-service research so readily as others, but in most there are several relevant master and doctorate degrees. Clinical tutors may sometimes be or come to be appropriate supervisors, but at the moment they are paid very little and their clinical duties are not always adequately reduced during their period of office. Greater recognition of their role in terms of both time and money, including recognised sessional commitments, is probably now necessary.

At present the South-west Thames Regional Health Authority is contributing over $£ 35000$ a year specifically to the more formal aspects of postgraduate medical training in psychiatry in its region. I have suggested some ways in which more than this needs to be spent in the immediate future. It may be that other regions are currently committed in various ways to the same extent or even more heavily. Meanwhile, even if the present unexpanded system described (uncomplicated by the much greater costs of in-service training) was uniformly applied to other specialties and all regions nationally and regionally, designated DHSS funds will be needed.

Finally, can one evaluate the impact of the expenditure of so much time and effort? An impression is gained easily enough and there are the college examination results to go by, but there are numerous variables impinging on the process. Now is the time, however, to set up some long-term attempt at evaluation, preferably inspired centrally by the need to fund the total federal exercise and the opportunity that this presents.

The above developments have been possible only because of the wholehearted collaboration and hard work of many people, particularly Dr E S Paykel, reader in psychiatry, St George's Hospital Medical School, and the clinical tutors in the region in 1973 and thereafternamely, Dr J A Birtchnell, Dr A A Black, Dr E G Lucas, Dr J S Stead, and Dr E D West. Professor G W A Dick, the regional postgraduate dean, has been a constant source of real support and guidance. Dr M A Fawkes, regional specialist in community medicine, Southwest Thames Regional Health Authority, has been especially helpful.

(Accepted 9 February 1977)
Panguma Catholic Hospital, Panguma, Sierra Leone

E KEANE, MB, MRCP, medical missionary

Liverpool School of Tropical Medicine, Liverpool L3 5QA

H M GILLES, MD, FRCP, professor of tropical medicine epidemiological features of the disease in this area. We have also included some data from Segbwema on 108 patients admitted with Lassa fever to the Nixon Memorial Hospital in 1975.

\section{Panguma Hospital}

The patients (all Africans) were admitted to hospital from the overcrowded general outpatient clinic, where patients with infectious disease cannot be isolated. Some were admitted direct to a four-bed isolation ward, but about $40 \%$ were initially barrier nursed in the general ward before being transferred to the isolation ward. Medical personnel only occasionally wore gowns, gloves, and masks and visitors never did so. Clinical examinations were conducted daily. Laboratory tests were carried out in the main hospital laboratory, no special precautions being taken.

Blood samples were obtained with a syringe and the serum stored in a refrigerator at $4^{\circ} \mathrm{C}$ until serological tests could be carried out by complement fixation (CF) or fluorescent antibody techniques. The diagnosis was confirmed serologically in 40 of the 156 Panguma patients and 11 of the 108 patients in Segbwema. 


\section{Ecology}

Panguma is at the centre of an area in the Eastern Province of Sierra Leone where Lassa fever is endemic (see figure). Many of the patients admitted to the Panguma Catholic Hospital and to the Nixon Memorial Hospital, Segbwema, come from a group of towns collectively known as Tongo, where a diamond mining company provides the livelihood of most of the men. Farming is the other main occupation. There is no water purification or sewage disposal

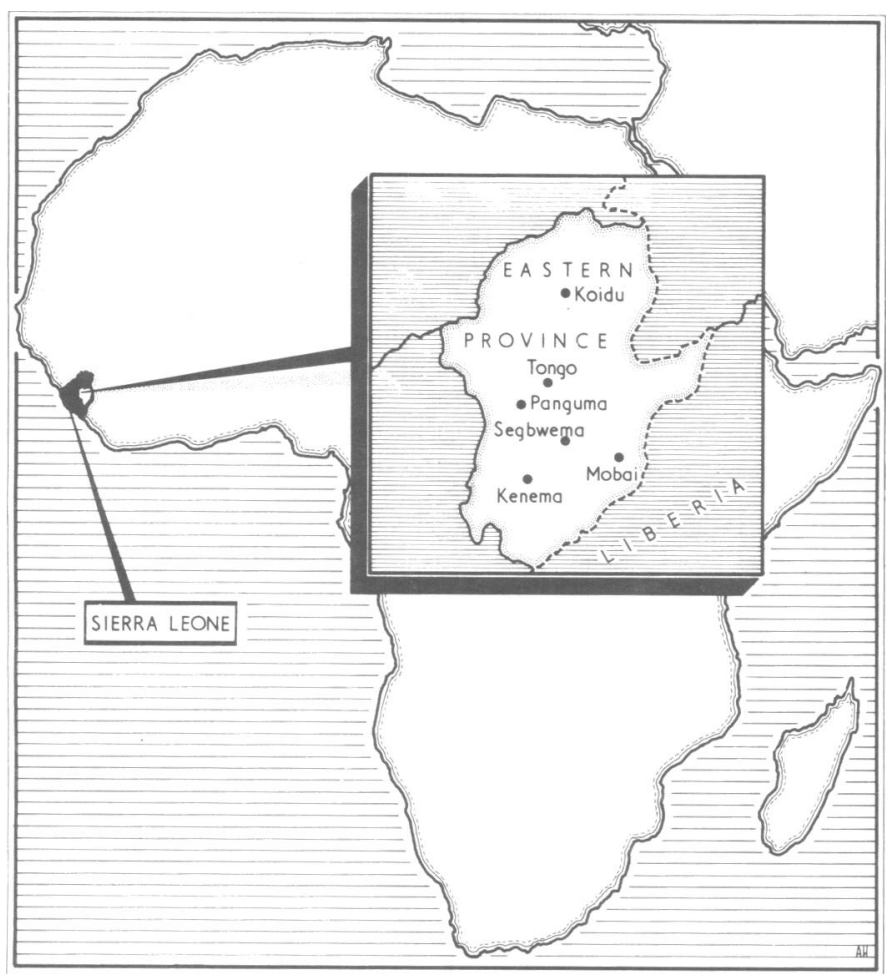

The Eastern Province of Sierra Leone, showing Panguma and Segbwema.

TABLE I-Symptoms and signs in 156 clinical cases of Lassa fever, Panguma Hospital 1973-6

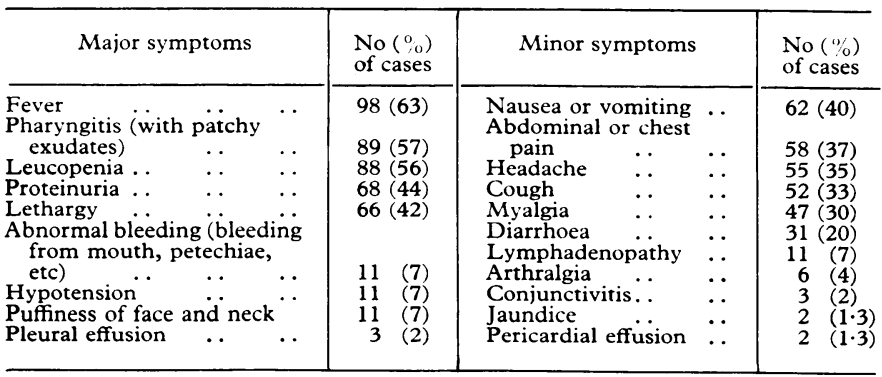

system. Several species of rodents inhabit the houses and shops and are a common source of complaint by the population.

\section{Clinical observations}

The clinical features (table I) in this series of 156 patients were similar to those described by Frame et al, ${ }^{2}$ White, ${ }^{3}$ and Monath et al. The most notable features were: $(a)$ a persistent fever of 38-41 C with daily swings of $2-3 \mathrm{C}$ which lasted from 6 to 30 days (average 16 days) and was occasionally accompanied by rigors; $(b)$ pharyngitis, characterised by reddening of the tonsillar tissues with raised patches of whitish or yellowish exudate; (c) an initial moderate leucopenia $2 \cdot 0-3 \cdot 0 \times 10^{9} / 1 ;(d)$ proteinuria; and $(e)$ a lethargy often out of proportion to the fever. Deafness was found in nine patients, but it is not known whether this was temporary or permanent. Three patients had a non-itchy papular rash on the front of the chest and neck. Alopecia, which has been described in other outbreaks, was not encountered.

\section{Seasonal distribution}

The monthly distribution of cases of Lassa fever in Panguma and Segbwema is shown in table II. Most cases seem to have occurred in January to March with a second peak in June and July. Before a seasonal incidence is accepted, however, further studies on population dynamics in both man and the rodent host are required.

\section{Sex and age distribution}

Ninety-two of the 156 patients seen in Panguma Hospital between January 1973 and March 1976 were men and 55 women. There were nine cases of Lassa fever in children. In Segbwema in 197536 of the patients with Lassa fever were men and 60 were women; only 12 patients were children. The adult patients were aged 19 to 60 years.

\section{Infection from patient to patient}

From 1973 to 1975 about 1000 patients a year were admitted to the general wards in Panguma Hospital. Those with Lassa fever were either barrier nursed in the general wards or put in a special side ward, which was separated from the main wards by only a linen screen. Relatives walked through the general ward whenever they visited patients with Lassa fever. But there were only two known cases of infection acquired in hospital during this period. A woman with Lassa fever who was being barrier nursed in the general ward transmitted the infection to the woman in the next bed, and this woman infected her young baby, whom she was breast feeding. Both adults recovered but the baby died.

Patients suspected of having Lassa fever often shared the isolation ward with those who were subsequently proved to have the disease. One such case occurred in Panguma where one woman with serologically proved Lassa fever $(\mathrm{CF}$ titre $>1 / 16)$ failed to infect her roommate, with whom she had shared the ward for nine days. The second woman's titre remained low $(<1 / 2)$. TABLE II-Monthly distribution of cases of Lassa fever in Panguma Hospital fanuary 1973-December 1975 and in Nixon Memorial Hospital, Segbwema,
fanuary-December 1975

\begin{tabular}{|c|c|c|c|c|c|c|c|c|c|c|c|c|c|}
\hline & Jan & $\mathrm{Feb}$ & Mar & April & May & June & July & Aug & Sept & Oct & Nov & Dec & Total \\
\hline \multicolumn{14}{|c|}{ Panguma } \\
\hline $\begin{array}{l}1973 \\
1974 \\
1975 \\
\end{array}$ & $\begin{array}{l}9 \\
2 \\
8 \\
\end{array}$ & $\begin{array}{l}8 \\
3 \\
7 \\
\end{array}$ & $\begin{array}{l}9 \\
3 \\
5\end{array}$ & $\begin{array}{l}2 \\
3 \\
2 \\
\end{array}$ & $\begin{array}{l}3 \\
2 \\
1 \\
\end{array}$ & $\begin{array}{r}15 \\
2 \\
7 \\
\end{array}$ & $\begin{array}{l}7 \\
1 \\
6\end{array}$ & $\begin{array}{l}2 \\
1 \\
4\end{array}$ & $\begin{array}{l}3 \\
1 \\
1\end{array}$ & $\begin{array}{l}1 \\
2 \\
2 \\
\end{array}$ & $\begin{array}{l}0 \\
2 \\
5\end{array}$ & $\begin{array}{l}1 \\
1 \\
3\end{array}$ & $\begin{array}{l}60 \\
23 \\
51\end{array}$ \\
\hline Total & 19 & 18 & 17 & 7 & 6 & 24 & 14 & 7 & 5 & 5 & 7 & 5 & 134 \\
\hline \multicolumn{14}{|c|}{ Segbwema } \\
\hline 1975 & 3 & 12 & 8 & 6 & 7 & 11 & 16 & 10 & 3 & 13 & 8 & 11 & 108 \\
\hline Grand total & 23 & 31 & 27 & 15 & 15 & 38 & 31 & 17 & 9 & 20 & 18 & 20 & 242 \\
\hline
\end{tabular}




In Jos, Nigeria, and Zorzor, Liberia, ${ }^{4}$; outbreaks of Lassa fever apparently resulted from person-to-person spread from the index case to other hospital patients. In Panguma Hospital this mode of ward infection was rare, despite the high annual turnover of patients and the continuous presence of Lassa fever among them (see table II).

\section{Infection from patient to hospital staff}

During the period under review 156 patients with suspected Lassa fever were seen in Panguma Hospital. The hospital employed 75 workers (doctors, nurses, nursing aids, laboratory assistants, and labourers). Of these, 50 had been in close contact with patients with Lassa fever or their specimens at some time during the three-year period studied.

One nurse and one nursing aid died; the aid was pregnant and it was not possible to confirm the diagnosis. Virus was isolated from the liver of the nurse ${ }^{\star}$ and her CF antibody titre was 1/32. Thirteen other hospital workers had antibody titres compatible with a diagnosis of recent Lassa fever infection $(1 / 8->1 / 64)$. Three were clinically ill but recovered, and the other 10 had no symptoms. Thus, out of 75 people at risk, 2 died, 13 were infected but recovered, and none of the remaining 60 developed Lassa fever despite the fact that the 44 who were tested had no antibodies to Lassa fever (CF antibody titre $<1 / 2)$. It is interesting to note that only two of the 95 people tested in a nearby hospital in Serabu had a positive CF titre to Lassa fever, while in Tongo Hospital only one out of 28 people tested was positive.

The high risk of infection among hospital staff that was reported in the epidemics at Jos and Zorzor was not paralleled in Panguma, where there were many close contacts and precautions against the spread of infection were poor. We cannot, of course, be sure that the hospital staff were infected inside the hospital.

\section{Infection from patient to relatives}

There is no catering in Panguma Hospital, so relatives visit the patients twice a day to bring them food. There are no barrier facilities. The relatives usually wait by the bedside until the patient has finished his food, frequently eat the leftovers themselves, wash the utensils at a tap within the hospital precincts, and return home. Despite the Piccadilly Circus-like atmosphere that exists at Panguma Hospital at meal times and the absence of barrier nursing precautions for relatives, there was only one possible case of person-to-person spread from an index case to a relative who brought food. When one considers that only $6-13 \%$ of the population have CF antibodies ${ }^{2}$ the epidemiological importance of person-to-person spread in the Panguma area must be limited. Since CF antibody to Lassa virus lasts only 1 to 5 years, its absence cannot be taken as evidence that the person has never been infected.

\section{Infection within households}

Several of the infected patients came from the same households. Table III gives details of patients from the same households who were admitted to Panguma Hospital in 1973-5. Members of all the affected households volunteered the information that their houses and the area around them were infested with rats.

One particular household deserves special mention. Ten people living in the household were infected at different times between September 1972 and January 1976 and admitted to Panguma Hospital. Two died. The owner of the house, however, never gave a history of clinical illness suggestive of Lassa fever and in 1976 his serum had positive CF antibodies to Lassa fever $(>1 / 8)$. Four of his wives had Lassa fever. In three of them, all of whom survived, the fever was proved serologically with CF titres greater than $1 / 64$. The fourth wife died in hospital of clinically diagnosed Lassa fever. The house has been rat infested for years and the Lassa fever virus was isolated from a Mastomys natalensis caught there. ${ }^{9}$

It is difficult to place a correct epidemiological interpretation on these household infections since there are at least two possibilities for transmission: person-to-person infection, or acquisition of Lassa fever from a common rat-infested source. Some of the patients were discharged from hospital when they were almost certainly still excreting virus (see 1973 data, table III). Yet despite this risk in a community with apparently little immunity there were no epidemics. The clustering of illness, the small percentage of seropositive people in compounds where cases had occurred $\left(13 \% \%^{2}\right)$, and the unimpressive evidence of person-to-person spread recorded earlier lead us to surmise that these household infections were more probably caused by transmission around a household focus of infected rodents than by person-to-person spread.

\section{Mortality}

Because of evidence (see below) that pregnant and puerperal patients are at greater risk from Lassa fever we assessed mortality in this group separately.

There were 138 non-pregnant patients in Panguma Hospital and 96 in Segbwema. Twenty-two $(15.9 \%)$ and $16(16.6 \%)$, respectively, of these patients died. There was no significant difference in mortality between men and non-pregnant women. Among the 18 women in Panguma who were pregnant or had just delivered their infants (within one month), however, the mortality was $33 \%$ (6 deaths). In Segbwema in 1975 the mortality among such women was $75 \%$ (nine out of 12 women died). The combined figures for pregnant women give a mortality of $50 \%$, which was significantly higher $\left(\chi^{2}=19.7 ; \mathrm{DF}=1 ; \mathrm{P}<0.001\right)$ than that for men and nonpregnant women. Similar findings have been recorded in the tropics for other infections - for example, pneumococcal meningitis, infectious hepatitis, and amoebiasis. Of the 12 pregnant patients who survived in Panguma Hospital, eight were followed to term: there were three stillbirths, but five pregnancies resulted in normal live infants, two of whom died within a few hours of birth.

The overall mortality rates in hospital cases in both Panguma in $1973-6(17.9 \%)$ and Segbwema in $1975(23.1 \%)$ were significantly lower than those recorded in previous epidemics (around $45 \%$ ).

It is not clear why the mortality in Sierra Leone was lower than that in Jos and Zorzor. In contrast to Panguma, the outbreaks in Jos and Zorzor seemed to be almost entirely hospital based and spread by person-to-person contact. There is some evidence that the Lassa virus in Sierra Leone may not be identical with that in Nigeria. ${ }^{5}$ These and other factors yet to be elucidated may be responsible for the striking differences in mortality between the areas.

TABLE III-Details of patients from the same households who were admitted to Panguma Hospital with suspected Lassa fever in 1973-5

\begin{tabular}{|c|c|c|c|c|c|c|}
\hline \multirow{2}{*}{ Year } & \multirow{2}{*}{$\begin{array}{l}\text { No of cases } \\
\text { of fever }\end{array}$} & \multirow{2}{*}{$\begin{array}{c}\text { No of households } \\
\text { with }>1 \text { member } \\
\text { affected }\end{array}$} & \multicolumn{4}{|c|}{ Household cases } \\
\hline & & & Patient & Admitted & Discharged & CF titre \\
\hline $\begin{array}{r}1974 \\
1975\end{array}$ & $\begin{array}{l}23 \\
51\end{array}$ & $\begin{array}{ll} & \\
4: & \text { Family A } \\
\text { Family B } \\
\text { Family C } \\
\text { Family D }\end{array}$ & $\begin{array}{l}\text { Man } \\
\text { Man } \\
\text { Man } \\
\text { Man } \\
\text { Father } \\
\text { Mother } \\
\text { Brother } \\
\text { Brother } \\
\text { Sister } \\
\text { Brother } \\
\text { Sister } \\
\text { Husband } \\
\text { Wife } \\
\text { Brother } \\
\text { Brother } \\
\text { Two brothers }\end{array}$ & $\begin{array}{l}2 \mathrm{Feb} \\
18 \mathrm{Feb} \\
15 \mathrm{March} \\
13 \mathrm{March} \\
25 \mathrm{March} \\
26 \mathrm{April} \\
31 \mathrm{Oct} \\
27 \mathrm{Nov} 1974 \\
11 \mathrm{Jan} \\
\text { Jan, together } \\
23 \mathrm{June} \\
2 \text { Aug } \\
\text { within } 3 \text { weeks } \\
\text { of each other }\end{array}$ & $\begin{array}{l}13 \text { Feb } \\
8 \text { March } \\
\text { Died } 16 \text { March } \\
22 \text { March } \\
29 \text { March } \\
14 \text { May }\end{array}$ & $\begin{array}{l}>1 / 8 \\
>1 / 8\end{array}$ \\
\hline
\end{tabular}




\section{Laboratory investigations}

The most consistent laboratory finding was a moderate leucopenia with a tendency for the white cell count to rise in the second week of the illness. Pronounced leucocytosis was, however, rare. Proteinuria was common. All the tests performed-blood counts, electrolyte and blood urea estimations, etc-were carried out in the general hospital laboratory. No special precautions were taken in handling the specimens. None of the five technicians used protective clothing, and none had antibodies to Lassa fever.

\section{Serology}

Serological tests were carried out in 45 of the 156 patients with clinically diagnosed Lassa fever, and the diagnosis was confirmed in 40 cases-a high order of accuracy in the circumstances. All the serological tests were carried out at the Microbiological Research Establishment, Porton Down, or at the Communicable Disease Centre, Atlanta.

\section{Treatment}

From 1973 to 197618 of the 156 patients received convalescent serum. Four of those who received the serum died. It is difficult to assess the value of convalescent serum but until there are better alternatives it should probably be given as early as possible. During the early acute stage of the disease rehydration and restoration of electrolytes are important.

\section{Conclusions}

A careful review of the 156 cases seen in Panguma together with those from Segbwema leads us to the following tentative conclusions.

(1) Lassa fever is endemic in this part of the Eastern Province of Sierra Leone.

(2) There are no absolute diagnostic clinical features. Persistent spiking fever, pharyngitis, leucopenia, and proteinuria, often unexplained, are strongly suggestive, especially when accompanied by abnormal bleeding.

(3) Pregnancy adversely influences the prognosis in Lassa fever.

(4) Epidemiological evidence in this area suggests that trans- mission from rodent to man may be commoner than spread from person to person.

(5) The epidemiological importance of Mastomys natalensis and the method of transmission from rodent to man needs investigation.

(6) In this area the disease seems neither so infectious nor so fatal as in previous epidemics. The epidemics in Jos and Zorzor may have been freak episodes rather than the common pattern of infection in endemic zones. On the other hand, we may be dealing with a different strain of virus with changed transmissibility or pathogenicity. Wulff and Large," however, noted no antigenic differences by the indirect immunofluorescence technique between Lassa virus strains isolated from Nigeria, Liberia, and Sierra Leone over six years. Nevertheless, more sensitive and specific techniques might reveal important differences.

(7) Until more detailed information is available on the mode of transmission of Lassa fever the present high security precautions will have to be maintained for medicolegal if for no other reasons.

(8) The treatment is basically supportive and can often be provided locally. When it cannot it is better to transport the equipment and staff needed than to send the patient out of the country.

Dr N Cochrane and Dr R Coles kindly provided us with the data on patients in Segbwema.

\section{References}

${ }^{1}$ Buckley, S M, and Casals, J, American fournal of Tropical Medicine and Hygiene, 1970, 19, 680.

2 Frame, J D, et al, American fournal of Tropical Medicine and Hygiene, 1970, 19, 670 .

${ }^{3}$ White, H A, Transactions of the Royal Society of Tropical Medicine and Hygiene, 1972, 66, 390.

${ }^{4}$ Monath, T P, et al, American fournal of Tropical Medicine and Hygiene, 1973, 22, 773.

${ }^{5}$ Monath, T P, et al, American Fournal of Tropical Medicine and Hygiene, 1974, 23, 1140.

${ }^{6}$ Woodruff, A W, et al, British Medical fournal, 1973, 3, 616.

7 Carey, D E, et al, Transactions of the Royal Society of Tropical Medicine and Hygiene, 1972, 66, 402.

${ }^{8}$ Winn, W C, jun, et al, Archives of Pathology, 1975, 99, 599.

${ }^{9}$ Monath, T P, et al, Science, 1974, 185, 263.

10 Wulff, $\mathrm{H}$, and Lange, J V, Bulletin of the World Health Organisation, $1975, \mathbf{5 2}, 429$.

(Accepted 31 March 1977)
What are the risks of malignancy in adults who had $x$-ray treatment for enlargement of the thymus in infancy?

Thyroid carcinoma and leukaemia have occurred in patients who have been treated with radiotherapy for enlargement of the thymus in their youth. One of the largest follow-up studies reported ${ }^{1}$ compared the incidence of malignant disease in 2878 treated patients and 5000 siblings; the total years that these two groups were at risk were 47313 and 46488 , respectively. Thirty-three malignancies were noted in the irradiated group compared with 14 in the control. In that study widefield irradiation with radiotherapy applied anteriorly and posteriorly resulted in an observed incidence of thyroid carcinoma of 14 when the expected would be 0.06 , and leukaemia of 3 when 0.43 would be expected. In the control groups the observed and expected incidence of these malignancies was about equal. When the area treated was small $(4 \mathrm{~cm} \times 4 \mathrm{~cm})$ there was no excess of thyroid carcinoma. The inference is, therefore, that the risk of thyroid carcinoma comes from the inadvertent irradiation of the thyroid. Generally any irradiation early in life will increase the risk of metastases or leukaemia. These risks are discussed in detail by Clemmesen.2

'Hempleman, L H, et al, fournal of the National Cancer Institute, 1967, 38, 317.
Clemmesen, J, in Advances in Acute Leukaemia, ed F J Cleton, D Crowther, and J S Malpas, p 1. Amsterdam, North Holland, 1974.
$A$ recent leading article on suppressing lactation disapproved of giving oestrogens because of the danger of thrombosis, and bromocriptine because it had other effects, and it recommended testosterone as a possibility. If testosterone is given what amounts would be recommended?

There is no unequivocal choice of a preparation to suppress lactation Some time ago a group of American physicians reviewed the characteristics of the ideal drug for suppressing lactation and came to the conclusion that no such compound existed. ${ }^{1}$ That was before the thromboembolic effects of oestrogens were recognised and before bromocriptine was available. There is little doubt about the grounds for disapproving of suppression of lactation by oestrogens; the editorial did no more than sound a note of caution about a drug as new as bromocriptine. In this impasse it is worth while considering all the alternatives. Clearly unnecessary medication should be avoided. If simple measures such as binders and sedatives are effective these are the treatment of choice. Bromocriptine is probably preferable to testosterone. Testosterone has been used more commonly in the United States than in Britain. There the usual technique is to give an injection of a long-acting compound at delivery. The preparation usually used contains $360 \mathrm{mg}$ of testosterone enanthate.

\footnotetext{
${ }^{1}$ Roland, M, Veprosky, E, and Linhart, W, American fournal of Obstetrics and
Gynecology, 1950, 70, 1004 .
} 